\title{
Embryonal Rhabdomyosarcoma of Adult Hypopharynx
}

\author{
Mahmudul Hasan ${ }^{1}$;Abdullah Al Mamun ${ }^{2}$, ABM Mashiur Rahman Chowdhury ${ }^{3}$; \\ Manash Ranjan Chakraborty ${ }^{4}$; Shahiduzzaman ${ }^{5}$; Khabiruddin Ahmed ${ }^{6}$
}

\begin{abstract}
Adult rhabdomyosarcoma in the head \& neck is extremely rare \& carries a poor prognosis. They should be considered as a distinct clinical entity. The authors report a case of embryonal rhabdomyosarcoma in an adult female in Hypopharynx treated with chemo-radiotherapy \& surgical excision., The patient responded to treatment \& 7 yrs later she is still alive with no signs of metastatic disease.
\end{abstract}

Key Words: Rhabdomyosarcoma; Hypopharynx.

\section{Introduction:}

Adult rhabdomyosarcoma in the Head \& Neck are extremely rare with poor prognosis ${ }^{1}$. They should be considered as a distinct clinical entity \&require different management from that of paediatric patient because there are possible disparities between adult rhabdomyosarcomas \& child patient which will be discussed -RMS is classified into three histological pattern $^{2}$ 1) Embryonal type 2) Alveolar type 3) Pleomorphic type Embryonal RMS generally occur in childhood \& rarely in adult.RMS is an aggressive malignant striated muscle neoplasm \& accounts for $50 \%$ of all paediatric soft tissue sarcomas ${ }^{3}$.Within the Head \& Neck, common sites are orbit, paranasal sinuses \& soft tissue of cheek \&neck ${ }^{3}$. Paroral RMS is rarely reported ${ }^{4,5}$. Tumours developing in a preexisting lesion is very rare ${ }^{6}$. The distinction between embryonal (ERMS) \& alveolar (ARMS) is critical because ARMS has a significantly worse prognosis compared with ERMS $^{+7}$. The majority of ARMS have a specific chromosomal translocation, which results in

\footnotetext{
1. Associate Professor, Dept. of Otolaryngology \& Head-Neck Surgery, Shaheed Suhrawardy Medical College \& Hospital, Dhaka. 2. Assistant Registrar, Dept. of Otolaryngology \& Head-Neck Surgery, Shaheed Suhrawardy Medical College \& Hospital, Dhaka 3. Senior Consultant , Dept. of Otolaryngology \& Head-Neck Surgery, Shaheed Suhrawardy Medical College \& Hospital, Dhaka 4. Junior Consultant, Dept. of Otolaryngology \& Head-Neck Surgery, Shaheed Suhrawardy Medical College \& Hospital, Dhaka 5. Professor of ENT, International Medical College

6. Professor \& Head, Dept of Otolaryngology \& Head-Neck Surgery,
}

Shaheed Suhrawardy Medical College \& Hospital, Dhaka

\section{Correspondence:}

Dr. Mahmudul Hasan

Associate Professor, Dept. of Otolaryngology \& Head-Neck Surgery,

Shaheed Suhrawardy Medical College \& Hospital, Dhaka fusion of the PAX3 on chromosome2 or the PAX7 gene on chromosome 1 with the FKHR gene or chromosome 13.The resulting fusion gene results ir the production of a protein product, which is believed to activate the myogenic transcription cascade contribute to oncogenic pathways ${ }^{8}$.The fusion produc can be detected by reverse transcriptase polymerase chain reaction (RT-PCR) and is diagnostic of ARMS $^{9}$ Histological diagnosis of RMS has improved markedly with the current use of immunohistochemistry, electror microscopy and molecular genetic studies'.We repor a case of Embryonal Rhabdomyosarcoma in an adul Hypopharynx treated with a combined modality treatment of chemotherapy , radiotherapy \& finally surgical excision as per the European Internationa Society of Paediatric Oncology (SIOP).She respondec to treatment \& 5 yrs later she is still alive.

\section{Case Report:}

A-20yrs old female patient with difficulty in swallowing $\&$ respiration (Tracheostomised),cachectic with $£$ mass in Hypopharynx referred to Shaheec Suhrawardy Hospital. On examination huge fleshy mass arising from right pharyngoepiglottic fold \& adjacent pharyngeal wall hanging downwards, which bleeds on touch.She was first seen in Sher-e-Bangla Medical College-ENT department on 30th June, 2004 at the age of $15 \mathrm{yr}$ with the complaints of throat pain \& difficulty in swallowing then they took biopsy from the lesion \& histopathology reported Fibrosarcoma (low grade).For this she got chemotherapy in Kolkata with Cisplatin,5-FU (one cycle) then she back to Dhaka \& received a course of radiotherapy (6600 cGy) at NICRH.Mohakhali,Dhaka. Later on she got another course of chemotherapy consisting Cisplatin,5FU,MTX,Bleomycin, Holoxan on Nov.2006 for her recurrence of lesion. But she was again seen in SAHIC, Dhaka for recurrence \& they surgically debulked the lesion per orally under G/A \& repeated debulking done in SAHIC by peroral route, then at last she reported to the first author on Nov. 2008, then the author done a lateral pharyngectomy \& excised the mass from right half of 
hypopharynx \& righl pharyngoepiglottic fold. After surgery her post operative period was unevenfull \& she was dischared on 10thpost operative day with closure of her previous tracheostomy \& she can take food per orally, then she was advised to report to NICRH,Mohakhali,Dhaka. Their next plan to give her chemotherapy consisting of Vincristine.ActinomycinD.Cyclophosphamide. She is still alive with no signs of recurrence.

\section{Discussion:}

Rhabdomyosarcoma is the most common head neck pediatric soft tissue sarcoma; however, it is important to recognize that this tumour can present in adults. RMS are thought to arise from primitive mesenchymal cells committed to develop into striated muscle ${ }^{10}$. In $1969 \mathrm{Li} \&$ Fraumeni ${ }^{11}$ suggested that genetic factor may play an important part in their pathogenesis \& they reported the increased incidence of breast carcinoma \& other malignant tumours in families of children \& young adults diagnosed with RMS11. Adult RMS in the head \& neck are very rare carry a poor prognosis ${ }^{12}$.About 60 New cases of RMS, mainly in children, are reported every year in the UK \& 350 new cases in the USA. Lloyd et $\mathrm{al}^{13}$, examined 54 patients with adult ERMS at theMemorial SloanKettering Cancer Center (MSKCC) in the USA' between 1950 \& 1978 \& they found only 4 cases in the head neck regions; all of them died with in 2 yrs.Hwkins et $\mathrm{al}^{14}$. analysed 84 adults RMS at the same centre between July 1982 \& December 1999 \& they found 20 cases in the head \& neck regions.Nayar et a $1^{15}$.found 26 Adult RMS in the head \& neck region \& only 2 cases in the nasopharynx between 1975 \& 1991 at the Institute Gustave Roussy (France). Ferrari et al. found 171 cases of adult RMS at the Institute Nazionale Tumori between 1975 \& 2001. Out of them 53 cases were in the head $\&$ neck regions.

In 1958, Horn \& Enterline ${ }^{16}$ outlined 4 histological subtype of RMS:embryonal, alveolar, botryoid, \& pleomorphic.ln children, the embryonal subtype is most common (50-60\%), in contrast to adults; and alveolar subtype is most common subtype seen under age 25.Pure pleomorphic subtype occurs almost exclusively in adults ${ }^{12}$.

Using immunohistochemistry tests, the tumour cells of the RMS express desmin, muscle specific actin, and myoglobin especially in welldifferfntiated tumour cells. These staining pattern decrease with poorly differentiated tumour cell; here vementin is strongly positive.Other new markers are MyoD1 \& myogenin antibodies42.The sign \& symptoms of RMS whether in adult or children, depend on the primary site of the tumour \& its invasion into adjacent structures.The adult RMS with sino nasal involvement present with nasal obstruction, epistaxis, sinusitis, otorrhoea, deafness \& local pain \& in advanced cases with cranial nerve palsy. The diagnosis of RMS must address two points: first, the nature and local extent of the primary diseases.This is established by multiple surgical biopsies; and once histological diagnosis is established,MRI or CT is performed to provide enough information for surgical resection \& radiotherapy treatment.Secondly.whether there are loco regional or distant metastases.Bone marrow biopsy.bone scanning, neck, chest, abdomen And pelvis CT scans are used for staging. Lumber puncture is performed in case of parameningeal involvement, which includes the nasopharynx, nasal cavity, middle ear \& both infratemporal \& pterygopalatine fossa ${ }^{1}$.The management of adult RMS in the head \& neck is complicated by inconsistent pathological diagnosis, small numbers of patients \& lack of prospective follow up , so there are widely divergent results of the success of management ${ }^{4}$, but they should be treated as pediatric RMS. Child patients are treated by a multimodal therapy, using a combination of surgery, chemotherapy and radiotherapy ${ }^{6}$.

The main histopathological feature is the presence of rhabdomyoblasts, which are large cells with a vacuolated eosinophilic cytoplasm \& the presence of cross striated muscle fibres. RMS often spread rapidly in the subepithelial tissuses, retaining a covering of stratified squamous epithelium. Hematogenous \& lymphatic metasteses occur rapidly. Adult RMS, especially the pleomorphic type, has been reported not to be radiosensitive2.

\section{Conclusion:}

Adult RMS in the head \& neck are extremely rare \& the 5 yr survival rate is $8 \%$ or less. They should be considered as a distinct clinical entity with special considerations for their management from that of pediatric RMS. At the moment they should be treated as pediatric patient, using a combination of surgery, chemotherapy \& radiotherapy because the 5 year survival rate of pediatric RMS significantly improved from $25 \%$ in 1970 to $75 \%$ in 1990.

\section{References:}

1.EL-GHAZALI AMS, MC LAREN KM, Embryonal Rhabdomyosarcoma of Adult Nasopharynx; the journal of Laryngology \& Otology, August 2005,vol-119, p-639-642.

2. Takeo Takahashi \& et al, Adult Embryonal Rhabdomyosarcoma in Axilla: Radiation medicine, 2003, vol21 No3, p-135-137.

3. Chirugupati R ,Alfatooni A. Myall RH, Hawkins D, Oda D. Orofacial Rhabdomyosarcoma in neonate \& young children: A review of literature \& management of four cases.Orofacial 
Oncology 2002; 38:508-515

4. Hoang MR Sinkve P, Albores-Saavedra J. Rhabdomyosarcoma arising in melanocytic nevus Am J Dermatopathol 2002: 24: 26-29.

5. Schmidt D.FIetcher CD, Hams D. Rhabdomyosarcoma with Embryonal Rhabdomyosarcoma of Adult Hypopharynx primary presentation in the skm.pathol Res Pract 1993;189:422-427.

6. Tulika S, Kempert P. Embryonal Rhabdomyosarcoma of lower lip, Indian paediatrics 2004; 41; 858-859. .

7. Kathelean T, Montone MD. \& et al, Embryonal \& alveolar Rhabdomyosarcoma of parameningeal sites in Adults a report of 13 cases. International Journal of surgical pathology. Feb 2009; 17(1);22-30

8. Grieman RB, Katsikeris NF, Symington JM. Rhabdomyosarcoma of the maxillary sinus: review of the literature \& report of a case. J Oral Maxillofacial Surgery.1988; 46; 1090-1096.

9. Koenigsberg RA. Noah R. Turtz A. et al: Rhabdomyosarcoma of the paranasal sinuses in adult. Clin Imaging 1995; 19:234-236.

10. Me Dowell HP. Update on childhood Rhabdomyosarcoma. Arch Pis Child 2003;88:354-7

11. Li FP, Fraumeni JF Jr. rhabdomyosarcoma in children: Epidemiologic study \& identification of a familial cancer syndrome. J natl cancer Inst 1969;43:1365-73

12. Hardaway CA, Graham BS, Bamette DJ, Feldman B Embryonal Rhabdomyosarcoma presenting in an adult; a ca report \& discussion of immunohistochemical staining. Am Dermatopathol 2003; 25: 45-52

13. Lloyd RV, Hajdu SI, Knapper WH. Embryor rhabdomyosarcoma in adults. Cancer 1983:51:557-65.

14. Hawkins DS, Anderson JR, Paidas CN, Wharam MD,Qualm SJ, Pappo AS, et al.Improved outcome for patients with middle e rhabdomyosarcoma: a children's oncology group study. J Clin On< 2001;19:3073-9

15. Nayar RC, Prudhomme F, Parise 0 Jr. Gandia D. Luboinski Schwaab G. Rhabdomyosarcoma of the head and neck in adults study of 26 patients. Laryngoscope 1993:103:1362-6

16. Ferrari A, Dileo RCasanova M, Bertulli R, Meazza C, Gandc L, et al.Rhabdomyosarcoma In adults.A retrospective analysis 171 patients treated as a single institution. Cancer 2003:98:571-81 